\title{
Mechanisms of Resistance to an Azole Fungicide in the Grapevine Powdery Mildew Fungus, Erysiphe necator
}

\author{
Omer Frenkel, Lance Cadle-Davidson, Wayne F. Wilcox, and Michael G. Milgroom
}

First and fourth authors: School of Integrative Plant Science, Section of Plant Pathology and Plant-Microbe Biology, Cornell University, Ithaca, NY 14853; second author: United States Department of Agriculture, Agricultural Research Service Grape Genetics Research Unit, Geneva, NY 14456; and third author: School of Integrative Plant Science, Section of Plant Pathology and Plant-Microbe Biology, Cornell University, Geneva, NY 14456.

Current address of first author: Department of Plant Pathology and Weed Research, Institute of Plant Protection, Agricultural Research Organization (ARO), The Volcani Center, Bet Dagan, 50250 Israel.

Accepted for publication 16 September 2014.

\begin{abstract}
Frenkel, O., Cadle-Davidson, L., Wilcox, W. F., and Milgroom, M. G. 2015. Mechanisms of resistance to an azole fungicide in the grapevine powdery mildew fungus, Erysiphe necator. Phytopathology 105:370-377.

We studied the mechanisms of azole resistance in Erysiphe necator by quantifying the sensitivity to myclobutanil $\left(\mathrm{EC}_{50}\right)$ in 65 isolates from the eastern United States and 12 from Chile. From each isolate, we sequenced the gene for sterol $14 \alpha$-demethylase (CYP51), and measured the expression of CYP51 and homologs of four putative efflux transporter genes, which we identified in the E. necator transcriptome. Sequence variation in CYP51 was relatively low, with sequences of 40 U.S. isolates

carried a previously identified A to $\mathrm{T}$ nucleotide substitution in position 495 (A495T), which results in an amino acid substitution in codon 136 (Y136F) and correlates with high levels of azole resistance. We also found a nucleotide substitution in position 1119 (A1119C) in 15 U.S. isolates, whose mean $\mathrm{EC}_{50}$ value was equivalent to that for the $\mathrm{Y} 136 \mathrm{~F}$ isolates. Isolates carrying mutation $\mathrm{A} 1119 \mathrm{C}$ had significantly greater CYP51 expression, even though A1119C does not affect the CYP51 amino acid sequence. Regression analysis showed no significant effects of the expression of efflux transporter genes on $\mathrm{EC}_{50}$. Both the $\mathrm{Y} 136 \mathrm{~F}$ mutation in $C Y P 51$ and increased CYP51 expression appear responsible for azole resistance in eastern U.S. populations of E. necator.
\end{abstract} identical to the reference sequence. Nine U.S. isolates and five from Chile
Pests and pathogens of all taxonomic groups invariably evolve resistance to pesticides or drugs aimed at their management (30). Human-pathogenic fungi have evolved resistance to antifungal drugs $(3,40)$, and, in agriculture, plant-pathogenic fungi have evolved resistance to fungicides used to manage plant diseases (28). Understanding the process by which fungicide resistance evolves is essential for delaying its development or managing it subsequently $(38,39)$. Most modern fungicides are considered to have single-site modes of action, to which high levels of resistance can evolve by a single mutation, sometimes resulting rapidly in disease control failures $(4,28)$. In contrast to the distinctively bimodal distributions of fungicide sensitivity to many fungicides-fungal individuals are either sensitive or resistantsensitivity to azole fungicides is a more continuous phenotype, and high levels of resistance evolve more slowly (13,22). Azole fungicides, which include triazoles and imidazoles, are the most widely used group of sterol $14 \alpha$-demethylation-inhibiting (DMI) fungicides for treating both human- and plant-pathogenic fungi. Quantitative variation in azole sensitivity is thought to result from multiple mechanisms and multiple genes contributing to resis-

Corresponding author: M. G. Milgroom; E-mail address: mgm5@cornell.edu

The first two authors contributed equally to this work.

* The $\boldsymbol{e}$-Xtra logo stands for "electronic extra" and indicates that the online version contains one supplementary table.

http://dx.doi.org/10.1094/PHYTO-07-14-0202-R

This article is in the public domain and not copyrightable. It may be freely reprinted with customary crediting of the source. The American Phytopathological Society, 2015 tance $(8,13,24)$. To fully understand and manage resistance to azoles, we need to understand the mechanisms and underlying genetics affecting these fungicides.

Reduced sensitivity to azoles occurs by three known mechanisms (13). The first involves target site mutations in the enzyme sterol 14 $\alpha$-demethylase (CYP51), a cytochrome P450 (CYP) monooxygenase essential for ergosterol biosynthesis in fungi. Several mutations in the gene CYP51 affecting the amino acid sequence are associated with reduced sensitivity to different azoles; the successive accumulation of these mutations in some fungi affects the range of different azoles to which sensitivity is reduced $(12,25)$. The second mechanism that reduces sensitivity is the constitutive overexpression of CYP51. Overexpression has been shown in several fungi to be caused by mutations in the promoter region upstream of $C Y P 51(27,33)$. The third mechanism involves the overexpression of genes that control the efflux of azoles out of fungal cells. Genes associated with efflux of fungicides are mainly ATP-binding cassette (ABC) transporters or major facilitator superfamily (MFS) transporters $(8,24)$. The types of mutations and mechanisms operating in a particular fungus have different effects on the azole sensitivity phenotype depending on which azole fungicide is used. Moreover, these genes or mutations may have epistatic effects depending on the genetic background of the fungal individual (12). Therefore, it would be helpful to understand resistance mechanisms for avoiding and managing azole resistance.

The grapevine powdery mildew fungus, Erysiphe necator (syn. Uncinula necator), is one of the first plant-pathogenic fungi in which mutations to CYP51 were shown to be associated with azole resistance (15). Resistance to azoles and other DMI fungicides has been described in North American and European populations of E. necator and in some cases has been associated 
with decreased disease control $(11,15,17,18,29,45)$. As found in other fungi, the distribution of sensitivities (expressed as $\mathrm{EC}_{50}$ ) was mostly continuous, and in some cases with distinctly higher mean $\mathrm{EC}_{50}$ values in populations exposed to applications of azoles $(11,18,43,45)$. Délye et al. (15) found a point mutation in CYP51 causing an amino acid substitution from tyrosine (Y) to phenylalanine $(\mathrm{F})$ in codon 136 (denoted Y136F), to be associated with a significant degree of azole resistance. This same amino acid substitution was later shown to account for a major portion of triadimenol resistance in the barley powdery mildew fungus, Blumeria graminis f. sp. hordei (44). Y136F has been found in azole-resistant isolates of E. necator in Virginia (11) and has been used for surveying some populations in France and Italy for azole resistance $(17,29)$. However, not all of the highly resistant isolates examined carried this mutation $(15,29)$, nor is resistance always high in isolates with Y136F (29). Such limitations in the correlation between the $\mathrm{Y} 136 \mathrm{~F}$ mutation and high levels of azole resistance indicate that monitoring populations for this mutation only is not adequate for estimating the frequency of azole resistance. It is more likely that multiple mechanisms confer resistance, and the distribution of azole sensitivity may vary among populations as a function of the frequencies of these mechanisms. Furthermore, knowing which mechanisms are operating might be useful in choosing which chemicals to apply because different CYP51 mutations or efflux transporters may affect cross-resistance relationships $(13,24)$.

As a nonmodel system, studies on the biology and genetics of E. necator are relatively challenging. For example, we have limited ability to obtain ascospores from controlled crosses (21, 35 ), preventing us from associating azole resistance with segregation of specific mutations, as is done with the cereal powdery mildew fungus, B. graminis (44), and a robust transformation system is not yet available for most powdery mildew fungi (9), precluding the option of gene-knockout experiments to determine the effects of specific genes on azole resistance phenotypes. Moreover, a genome sequence of E. necator is not yet available, as it is for two formae speciales of $B$. graminis and two powdery mildew species that infect Arabidopsis $(34,42)$. However, the transcriptome of one North American isolate was sequenced recently and includes homologs of the $\mathrm{ABC}$ and MFS transporter genes associated with azole sensitivity in other fungi (L. CadleDavidson and M. G. Milgroom, unpublished results). Identifying these homologous sequences makes it possible to test whether their expression correlates with azole sensitivity in E. necator. Similarly, we can determine the expression levels of CYP51, even though the promoter sequence is not available. To study these relationships, we looked for associations between azole sensitivity phenotypes and mutations in CYP51 and expression of candidate efflux transporters in samples from a diverse, sexually reproducing population of E. necator.

The primary objectives for this study were to (i) determine the distribution of sensitivity to the azole fungicide myclobutanil in a diverse, native population of E. necator in the eastern United States, and (ii) determine whether mutations and expression of CYP51 and expression of ABC transporter and MFS genes significantly contribute to variation in myclobutanil sensitivity. A secondary objective was to look for correlations between these same traits and myclobutanil sensitivity in a sample of E. necator isolates collected from vineyards in Chile, where resistance to azoles was suspected.

\section{MATERIALS AND METHODS}

Sampling of $\boldsymbol{E}$. necator. We analyzed azole sensitivity in samples of E. necator collected from the eastern United States, where it is native, and from Chile, where it was introduced. A complete list of isolates and their hosts and geographic origins is found in the Supplemental Table 1. Of the 65 isolates from the eastern United States, 28 were collected from wild hosts ( $V$. aestivalis, V. labrusca, V. riparia, and V. rotundifolia), and 37 were from cultivated grapevines ( $V$. vinifera, $V$. rotundifolia, Vitis $\times$ labrusca, and Vitis interspecific hybrids). The eastern U.S. population is phenotypically diverse (19), reproduces sexually (6), and shows very little genetic structure (20). In contrast, populations outside the eastern United States, including California, are much less diverse and are composed of one or two reproductively isolated genetic groups (A and B) $(5,20)$. Twelve isolates of E. necator were sampled in 2007 and in 2008 from commercial vineyards in northern Chile (Region IV, vicinity of La Serena), in which the control of grapevine powdery mildew provided by azole fungicides appeared to be substandard. Grapevine powdery mildew was first reported in Chile in 1862 on imports of $V$. vinifera from Europe (14), and therefore we predicted that this population of E. necator had low diversity as do other introduced populations. Because of the genetic differences between native and introduced populations, samples from the eastern United States and Chile were analyzed separately. All isolates were maintained in the laboratory on surface-disinfested grape leaves and cultured for quantifying azole sensitivity and nucleic acid purification as described previously (19).

Azole sensitivity assay. We used the assay described by Erickson and Wilcox (18) to quantify the sensitivity of E. necator to the azole fungicide myclobutanil. This fungicide is commonly used to manage grapevine powdery mildew, and sensitivity of $E$. necator to it is highly correlated with sensitivity to other azole fungicides $(11,18,45)$. The assay is based on inoculating leaf disks treated with different fungicide concentrations and quantifying colony growth. Technical-grade myclobutanil was dissolved in acetone and diluted with Nanopure type 1 water containing $0.05 \%$ Tween 20 to concentrations of $1,0.5,0.25,0.06$, and $0.016 \mu \mathrm{g} / \mathrm{ml}$. The concentrations of acetone in these solutions did not affect the growth and conidiation of E. necator (18). Disks (9 mm diameter) were cut from surface-sterilized young leaves of $V$. vinifera 'Riesling' grown in a walk-in biotron. Each leaf disk was soaked for $60 \mathrm{~min}$ in a myclobutanil solution, dried, and placed on $1.5 \%$ water agar. Leaf disks soaked in Nanopure type 1 water with $0.05 \%$ Tween 20 were used as the control. Leaf disks were inoculated by transferring a conidial chain from the inoculum source, as described previously (18), and incubated at room temperature $\left(25^{\circ} \mathrm{C}\right)$ for 7 days with $12 \mathrm{~h}$ light/12 $\mathrm{h}$ dark cycles, at which time the maximum colony radius was measured under a dissecting microscope at $32 \times$ magnification. Four replicate disks were used for each concentration per isolate. The effective concentration to reduce colony growth by $50 \%\left(\mathrm{EC}_{50}\right)$ was determined by regressing the percent of colony growth relative to the control treatment on the logarithm of fungicide concentration as described previously (18).

Cyp51 sequencing. Using polymerase chain reaction (PCR), we amplified CYP51 and Sanger-sequenced PCR products at the Cornell University Life Sciences Core Laboratories Center. We used sequences of CYP51 in GenBank accessions EF649776.1 and U72657 to design three sets of primers using Primer3 (37) to amplify $1,682 \mathrm{bp}$ of the coding region (Table 1). Because the beginning of the coding region was not suitable for primer design, we used accession U72657 (15) to design the first primer; the rest were designed from accession EF649776.1. The sequence in U72657 includes $203 \mathrm{bp}$ in the upstream noncoding region and allowed us to design a forward primer for amplifying the beginning of the coding region. Sequences from the three parts of the gene were concatenated using Vector NTI (Life Technologies, Grand Island, NY), and a multiple alignment was constructed in ClustalW (36) to determine single-nucleotide polymorphisms (SNPs) and haplotypes.

Identification of homologs of $\mathrm{ABC}$ and MFS transporters in E. necator. $\mathrm{ABC}$ and MFS transporter genes associated with azole resistance in ascomycetes $(8,23,24)$ were used to search for 
homologs in an early draft of an E. necator transcriptome sequence (C. Cadle-Davidson and M. G. Milgroom, unpublished data). Amino acid sequences of the following genes were used in this query: MFS gene Bcmfsl (DHA14-like major facilitator, GenBank no. AAF64435.2), BcatrD protein (GenBank CAC41639.1) and BMR1 (GenBank BAA93677.1) from Botrytis cinerea (teleomorph Botryotinia fuckeliana), and CDRI (GenBank no. CAA54692.1) from Candida albicans. cDNA sequences in the $E$. necator transcriptome were translated in all reading frames into amino acid sequences using tBLASTn software at the Cornell University bioinformatics high-performance computing (BioHPC) facility for query using amino acid sequences of the above efflux transporters. Sequences in the E. necator transcriptome were identified as putative homologs based on sequence similarity and then blasted against the NCBI database using PBLAST to confirm their homology with additional fungi. Sequences with high sequence similarity were considered homologs. The same strategy was used to identify homologs of actin. Homologs to histone $\mathrm{H} 3$ and $\beta$-tubulin were identified in E. necator previously $(1,41)$.

Quantitative reverse-transcription PCR (qRT-PCR) for quantification of gene expression. We quantified the expression of genes by qRT-PCR using methods described previously for $E$. necator (41). Isolates were cultured on surface-sterilized detached leaves of $V$. vinifera 'Cabernet Sauvignon' for 8 days at $23^{\circ} \mathrm{C}$ in $12 \mathrm{hr}$ light/12 hr dark conditions. Mycelia and conidia were harvested by applying fingernail polish over the colony and leaf surface and peeling it off when it was dry (7). Total RNA was isolated using RNeasy (Qiagen, Valencia, CA), as described by Cadle-Davidson et al. (7). We used the iScript cDNA Synthesis Kit (Bio-Rad, Carlsbad, CA) to synthesize cDNA. This process was repeated for all isolates and constituted biological replicates; three replicates were obtained for some isolates.

For each RNA isolate, we performed qRT-PCR using a MyiQ thermal cycler (Bio-Rad). Reactions included 1.5 $\mu \mathrm{M}$ Syto 9 for product quantification (Invitrogen, Grand Island, NY), and $10 \mathrm{nM}$ fluorescein (Sigma-Aldrich, St. Louis, MO) for well-factor normalization. qRT-PCR was performed twice for each RNA sample (technical replicates), and estimates were averaged for statistical analyses. PCR primers were designed from transcriptome sequences using Primer3 for CYP51 and all homologs (Table 1). We normalized expression data for candidate genes by the expression of three constitutively expressed reference genes: actin, $\beta$-tubulin, and histone $\mathrm{H} 3$ (Table 1). The control for estimating relative expression was calculated as the average of three E. necator isolates with $\mathrm{EC}_{50}$ values close to the mean baseline sensitivity of 0.01 to $0.02 \mathrm{ppm}$ (18). To minimize any possible selection by exposure to azoles or other fungicides, or recombination with resistant isolates, we chose control isolates that were collected from wild Vitis species in Panther Creek State Park (Blood Mountain, GA), and Brevard, NC, more than $10 \mathrm{~km}$ from any known vineyards (19). To calculate relative gene expression we used the formula given by Pfaffl (32):

$$
\text { ratio }=\frac{\left(E_{\text {target }}\right)^{\Delta C P_{\text {target }}(\text { control-sample })}}{\left(E_{\text {ref }}\right)^{\Delta C P_{\text {ref }}(\text { control-sample })}}
$$

where $E_{\text {target }}$ and $E_{\text {ref }}$ are the amplification efficiency of the target genes and the reference (or normalizing) genes, respectively, and $\Delta \mathrm{CP}_{\text {target }}$ and $\Delta \mathrm{CP}_{\text {ref }}$ include the differences in expression between the test isolates and the mean of three control isolates for the target and reference genes, respectively.

Statistical analyses. We used stepwise regression to determine which factors were associated with variation in the logarithm of $\mathrm{EC}_{50}$ values. Variables used in the model included mutations in CYP51 sequences, expression of CYP51, expression of each of the ABC and MFS transporter homologs, and all possible twoway interactions between these variables. The probability for a variable to enter was set at $\alpha=0.2$, and the probability to leave the model was set at $\alpha=0.1$. All analyses were done using JMP5 (SAS, Cary, NC).

TABLE 1. Primers used for sequencing CYP51 and quantitative reverse-transcription polymerase chain reaction (RT-PCR)

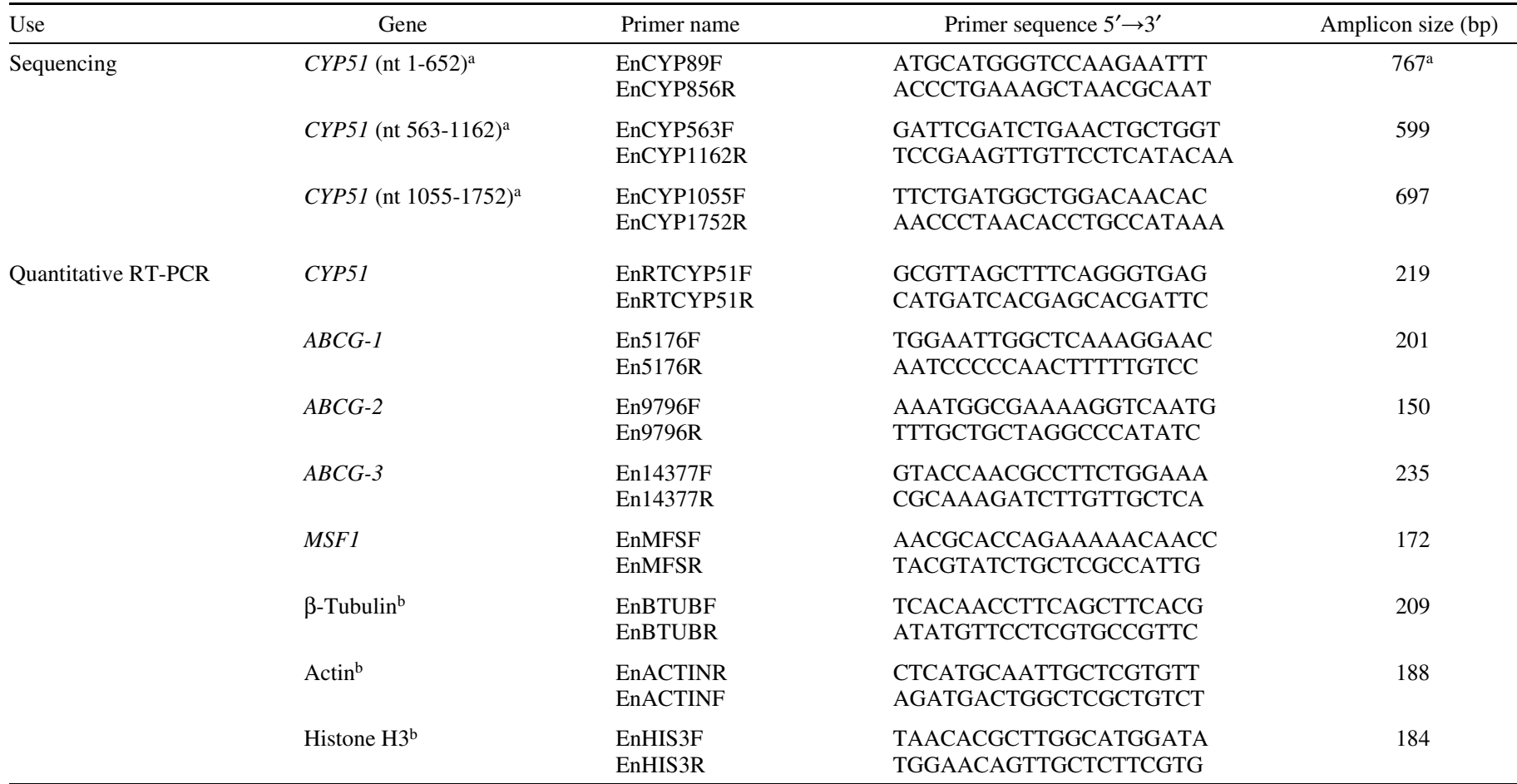

\footnotetext{
a Nucleotide sites are relative to the reference CYP51 sequence in GenBank accession EF649776.1. The forward primer for the first segment of the coding region (EnCYP89F) was designed using GenBank accession U72657 (15) and includes 204 bp upstream from the coding region.

${ }^{\mathrm{b}}$ Genes used for normalizing expression data (Materials and Methods). Primers for histone H3 were designed by Wakefield et al. (41).
} 


\section{RESULTS}

Distribution of azole sensitivity. $\mathrm{EC}_{50}$ values for myclobutanil varied over more than two orders of magnitude (0.007 to $3.54 \mu \mathrm{g} / \mathrm{ml}$ ) among the isolates of E. necator examined, and therefore we present their distribution on a log scale (Fig. 1). Although phenotypes were found throughout the range of values encountered, the distribution of $\log \mathrm{EC}_{50}$ values within this range was distinctly bimodal in both the United States and Chile, with the two peaks at approximately 0.03 and $0.56 \mu \mathrm{g} / \mathrm{ml}$ for the moreversus less-sensitive groupings, respectively, consistent with previously documented distributions in E. necator populations with significant DMI fungicide exposure versus those from baseline populations $(18,43)$.

Sequence variation in CYP51. We found five haplotypes among the 65 CYP51 sequences determined for isolates from the eastern United States (Table 2). The most common haplotype was found in 40 isolates; we refer to this as the wild type $\left(\mathrm{CYP}^{+} \mathrm{I}^{+}\right)$ because it is the most common and is not associated with myclobutanil resistance (see below). Nine isolates carried haplotype CYP51 ${ }^{\mathrm{A} 495 \mathrm{~T} / \mathrm{A} 1170 \mathrm{C}}$, which is characterized by mutations at nucleotides 495 and 1170 relative to the wild type. The mutation at nucleotide 495 causes a tyrosine to phenylalanine substitution in codon $136(\mathrm{Y} 136 \mathrm{~F})$ and is known to confer azole resistance

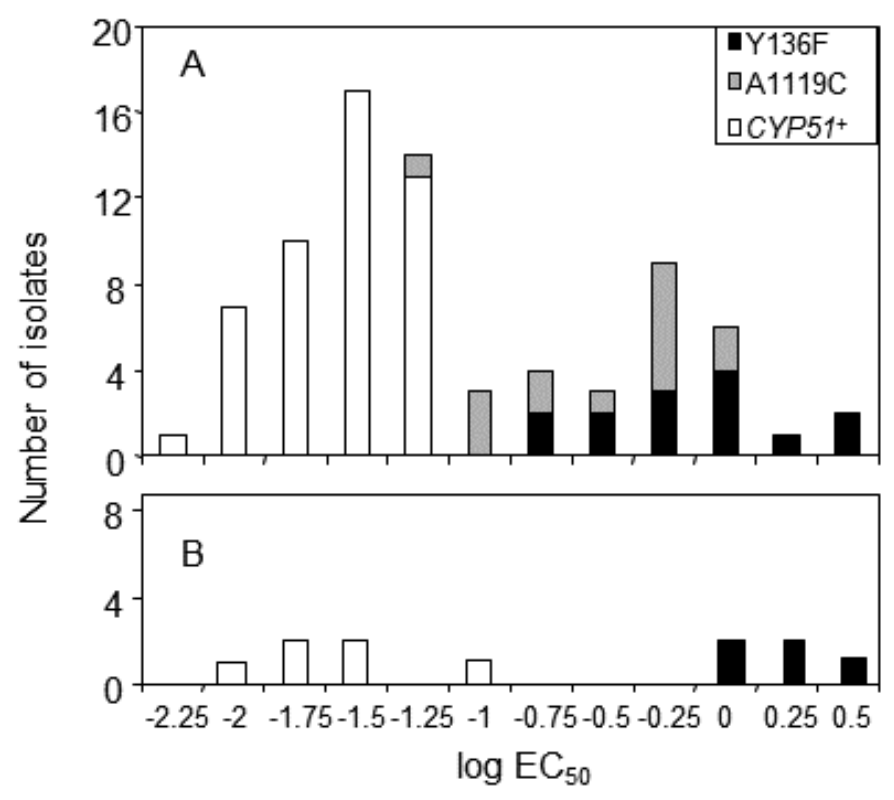

Fig. 1. Distribution of myclobutanil sensitivity among isolates of Erysiphe necator, expressed as $\log \mathrm{EC}_{50}(\mu \mathrm{g} / \mathrm{ml})$ in isolates from the $\mathbf{A}$, eastern United States and B, Chile. Two mutations in the CYP51 gene that correlate with reduced sensitivity to azole fungicides are mapped onto the distribution, indicated by amino acid substitution Y136F (15) and a synonymous nucleotide substitution A1119C. Isolates without either of these mutations are considered to be wild type, $C Y P 51^{+}$. in E. necator (15), whereas the mutation at nucleotide 1170 (A1170C) is a synonymous mutation in codon 343. Two other haplotypes also share the A1170C mutation. We found an additional mutation, $\mathrm{A} 1119 \mathrm{C}$, which is a synonymous mutation in codon 326, in haplotypes CYP5 $1^{\mathrm{A} 1119 \mathrm{C}}$ and CYP51 $1^{\mathrm{A} 1119 \mathrm{C} / \mathrm{A} 1170 \mathrm{C}}$ (Table 2).

Only two haplotypes were found among the 12 isolates from Chile. Seven carried haplotype $C Y P 51^{\mathrm{C} 608 \mathrm{~T}}$, which is identical to the reference haplotype in accession EF649776.1 (accession no. KM077176) and five carried CYP51 which has the Y136F amino acid substitution. Mutation C608T results in an amino acid difference from isoleucine to threonine in codon 156 (I156T). This amino acid substitution is characteristic of a known difference between genetic groups A and B in Europe but is not associated with azole resistance (16). Microsatellite genotyping of a sample of Chilean isolates confirmed they were in group B (data not shown).

All isolates carrying the $\mathrm{Y} 136 \mathrm{~F}$ mutation, from both the United States and Chile, were at the higher end of the $\mathrm{EC}_{50}$ distribution (Fig. 1, Table 2). Similarly, U.S. isolates carrying the mutation A1119C also had high $\mathrm{EC}_{50}$ values, even though this mutation does not change the CYP51 amino acid sequence. $\mathrm{EC}_{50}$ values of isolates with either the Y136F or A1119C mutation were significantly greater $(P<0.001)$ than those without these mutations. There was no significant difference in mean $\mathrm{EC}_{50}$ values between U.S. isolates carrying the $\mathrm{A} 1119 \mathrm{C}$ versus the $\mathrm{Y} 136 \mathrm{~F}$ mutation $(P=0.23)$. Of the 20 isolates carrying mutation $\mathrm{A} 1170 \mathrm{C}, 18$ had haplotypes with either amino acid substitution $\mathrm{Y} 136 \mathrm{~F}$ or mutation A1119C. However, the two CYP51 ${ }^{\mathrm{A} 1170 \mathrm{C}}$ isolates, in which no other mutations to the gene occurred, had low $\mathrm{EC}_{50}$ values (Table 2 ), suggesting that this mutation alone is not associated with azole resistance.

Expression of CYP51. We obtained expression data for CYP51 from 47 E. necator isolates from the eastern United States and seven from Chile. Several isolates were lost before we could culture them for RNA isolation; therefore, our sample sizes are smaller for CYP51 expression than for nucleotide sequences. Overall, the logarithm of CYP51 expression was positively correlated with $\log \mathrm{EC}_{50}$ for myclobutanil in the United States $(r=$ $0.50, P<0.001)$ (Fig. 2). Relative to isolates carrying the wildtype haplotype, expression was significantly $(P<0.001)$ higher for isolates carrying either the Y136F mutation or the A1119C mutation, even though the amino acid sequence for the latter group was identical to that of the wild type (Fig. 3). CYP51 expression was also significantly greater in isolates carrying the A1119C mutation than in isolates carrying Y136F $(P<0.001)$. The mean $\log$ expression of the Chilean isolates carrying the Y136F mutation was two times greater than those without Y136F but was not significantly different $(P=0.19)$ due to small sample sizes.

Identification and expression of $\mathrm{ABC}$ transporter and MFS homologs in $\boldsymbol{E}$. necator. We identified three $\mathrm{ABC}$ transporter homologs in the subgroup $A B C G$ and one $M F S$ homolog in the $E$. necator transcriptome (Table 3). We refer to these homologs as

TABLE 2. Frequency of CYP51 haplotypes in populations of Erysiphe necator in the eastern United States

\begin{tabular}{|c|c|c|c|c|c|c|c|}
\hline \multirow[b]{2}{*}{ Haplotype } & \multirow[b]{2}{*}{$N$} & \multirow{2}{*}{$\begin{array}{c}\text { Deposited } \\
\text { accession number }\end{array}$} & \multirow[b]{2}{*}{ Mean $\log \left(\mathrm{EC}_{50}\right)$} & \multirow[b]{2}{*}{ Mean $\mathrm{EC}_{50}$} & \multicolumn{3}{|c|}{ Nucleotide sites $^{\mathrm{a}}$} \\
\hline & & & & & 495 & 1119 & 1170 \\
\hline $\mathrm{CYP} \mathrm{I}^{+}$ & 40 & KM077178 & $-1.469 \pm 0.048$ & $0.041 \pm 0.004$ & $\mathrm{~A}$ & A & $\mathrm{A}$ \\
\hline CYP51 $1^{\mathrm{A} 1170 \mathrm{C}}$ & 2 & КМ077180 & $-1.699 \pm 0.301$ & $0.025 \pm 0.015$ & A & A & $\mathrm{C}$ \\
\hline CYP51 & 9 & KM077181 & $-0.453 \pm 0.134$ & $0.438 \pm 0.121$ & A & $\mathrm{C}$ & $\mathrm{C}$ \\
\hline CYP51 $1^{\mathrm{A} 1119 \mathrm{C}}$ & 6 & KM077182 & $-0.385 \pm 0.143$ & $0.587 \pm 0.149$ & A & $\mathrm{C}$ & A \\
\hline
\end{tabular}

${ }^{a}$ Nucleotide sites are relative to the reference CYP51 sequence in GenBank accession EF649776.1, which differs from the eastern U.S. wild-type CYP51 ${ }^{+}$by nucleotide substitution C608T.

${ }^{b}$ Nucleotide substitution from A to $\mathrm{T}$ in position 495 causes an amino acid substitution from tyrosine (Y) to phenylalanine (F) at codon 136, Y136F. Nucleotide substitutions found at positions 1119 and 1170 in the United States are synonymous mutations in codons 326 and 343, respectively. 
$A B C G-1,-2,-3$ and $M F S 1$, respectively. To estimate the contribution of these four homologs to reduced azole sensitivity, regression analyses were conducted on $\log \mathrm{EC}_{50}$ values using expression data from 47 isolates from the eastern United States. Because of the markedly bimodal distribution of $\log \mathrm{EC}_{50}$ values, with isolates carrying mutations Y136F and A1119C more resistant than the others (Fig. 1), we conducted regressions on each group separately to see if any other factors could explain the remaining variance. No significant factors were found by regression within either group. Similarly, nearly all of the variance in $\log \mathrm{EC}_{50}$ in the small sample from Chile was explained by mutation Y136F (data not shown).

\section{DISCUSSION}

Azole sensitivity in E. necator can be reduced by three known mechanisms: variation in the amino acid sequence of CYP51, overexpression of CYP51, and efflux transporters that pump azoles out of cells. The first two of these mechanisms were responsible for reduced sensitivity to myclobutanil in E. necator isolates from the eastern United States and Chile. Amino acid substitution Y136F alters the target site in CYP51 and is well known for its effect on azole resistance in E. necator (15) and other fungi $(28,44)$. Y136F appeared to have a major effect on the myclobutanil sensitivity of the E. necator isolates investigated in this study. Approximately half of the most resistant isolates from the eastern United States and all of the most resistant isolates from Chile carry this mutation, whereas none of the most sensitive isolates do. Interestingly, the other half of the most resistant isolates from the eastern United States carry the synonymous mutation $\mathrm{A} 1119 \mathrm{C}$ in $C Y P 51$. Isolates carrying this mutation have $\mathrm{EC}_{50}$ values equal to those with Y136F (Fig. 1, Table 2).

The significant correlation of nucleotide substitution A1119C in CYP51 with azole resistance cannot be explained by an alteration of the target site because this mutation does not affect the amino acid sequence. However, isolates carrying this mutation overexpress CYP51 (Figs. 2 and 3), which is an important mechanism known to contribute to azole resistance $(27,33)$. In other fungi, overexpression of CYP51 can be caused by mutations in the promoter region. For example, a transposable element inserted into the promoter of CYP51 in Monilinia fructicola alters gene expression (26). However, we can only speculate on the cause of overexpression of CYP51 in E. necator because the promoter sequence has not been isolated reproducibly (despite several attempts in our laboratories). The simplest explanation for this correlation is that a mutation in the promoter conferring over-

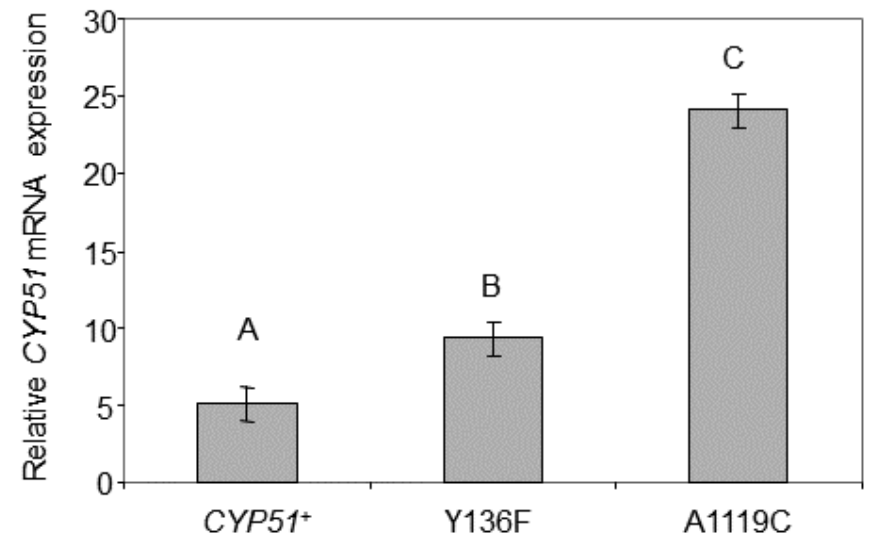

Fig. 3. Histogram of mean CYP51 expression for Erysiphe necator isolates carrying the azole-sensitive wild-type reference haplotype or mutation A1170C alone $\left(C Y P 51^{+}\right)$or mutations Y136F and A1119C. Expression data were normalized by the expression of the constitutively expressed reference genes actin, $\beta$-tubulin, and histone $\mathrm{H} 3$ relative to the average of three sensitive, wild-collected control isolates, as detailed in the Methods. Significant differences were found between all pairs of mutations by Tukey's honest significant differences (HSD) test. Different letters above each bar denote the significant difference at $P<0.05$.

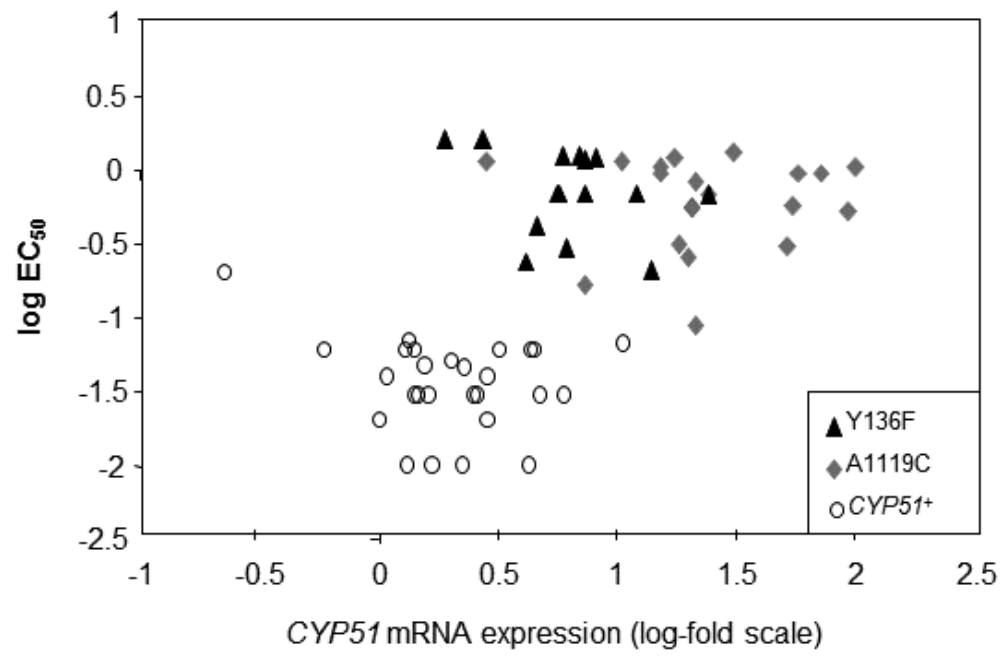

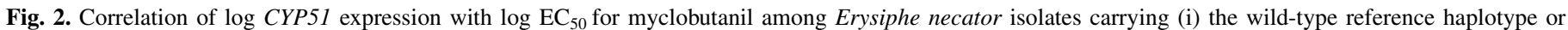
mutation A1170C alone (CYP51+), (ii) the Y136F amino acid substitution, or (iii) the nucleotide substitution A1119C.

TABLE 3. Homologs of efflux transporter genes found in the transcriptome sequence of Erysiphe necator using a tBLASTn search

\begin{tabular}{|c|c|c|c|c|}
\hline Gene & GenBank accession used as query & E. necator contig & E. necator GenBank accession & E-value \\
\hline$A B C G-1$ & CAA54692.1 CDR1 (Candida albicans) & En5176 & KM217169 & $2 \mathrm{e}-17$ \\
\hline$A B C G-2$ & BAA93677.1 BMR1 (Botrytis cinerea) & En7679 & KM217168 & $3 e-22$ \\
\hline$A B C G-3$ & BAA93677.1 BMRl (B. cinerea) & En14377 & KM217167 & $2 \mathrm{e}-118$ \\
\hline MFS1 & AAF64435.2 Botrytis MFS ${ }^{\text {a }}$ transporter Bcmfs 1 (B. cinerea) & En3478 & KM217170 & $2 \mathrm{e}-62$ \\
\hline
\end{tabular}

${ }^{a} \mathrm{MFS}=$ major facilitator superfamily. 
expression originally occurred by coincidence in an individual carrying the A1119C mutation, increased in frequency because of selection by fungicide applications, and later migrated widely throughout the eastern United States However, because the two mutations are tightly linked (on the order of about $2 \mathrm{kbp}$ ), overexpression and $\mathrm{A} 1119 \mathrm{C}$ are in linkage disequilibrium. In this scenario, linkage disequilibrium is transient and decays over time, albeit very slowly because recombination must occur between the promoter and nucleotide site 1119 . In the long run, however, A1119C would eventually become an unreliable marker for this type of myclobutanil resistance. Alternatively, we speculate that this mutation could affect mRNA stability, for example by altering secondary and/or tertiary structure, although we have no evidence to support that hypothesis. Based on in silico analysis using the RNAz algorithm (http://rna.tbi.univie.ac.at/RNAz), it appears that nucleotide 1119 is flanked by, but is not within, a region of secondary structure, and the alleles described here do not affect the predicted structure (data not shown). To assess the risk of resistance because of overexpression of CYP51 more directly, mutations in the promoter will need to be identified in future studies.

We found no evidence for a role of efflux transporters in azole resistance in E. necator. The expression of E. necator ABCG and MFS transporter homologs had no significant effects in the regression analysis after accounting for the effects of mutations $\mathrm{Y} 136 \mathrm{~F}$ and $\mathrm{A} 1119 \mathrm{C}$. In other fungi, $\mathrm{ABC}$ transporters classified as ABCG are known to function as pleiotropic drug resistance $(P D R)$ genes (23) and have been shown experimentally to affect the efflux of azoles (8). However, we tested for sensitivity to only a single azole fungicide, and it is possible these transporters may confer a degree of resistance to other members of the group. At the time this study was conducted, these four homologs were the only ones we could find in the E. necator transcriptome. A search in a more complete transcriptome sequence in the future would be needed to determine whether other transporter genes have more effect on azole sensitivity. For example, efflux transporters in subfamilies $\mathrm{ABCB}$ and $\mathrm{ABCC}$ are involved with drug resistance, including resistance to azoles, in other ascomycetes (23). Their role in azole resistance should also be tested in future studies of E. necator for resistance to myclobutanil and other azole fungicides.

We present correlative data for making inferences on the role of mutation Y136F and overexpression of CYP51 as major mechanisms of azole resistance in eastern U.S. populations of $E$. necator. These correlations, as well as the regression analyses to evaluate the effects of efflux transporter gene expression, are justified by three factors. First, the mechanisms we identified are well-known to contribute to azole resistance in other fungi $(8,13,24)$. Second, the experimental approaches available for studying model fungi are not yet available for E. necator. In other fungi, mechanisms of azole resistance have been inferred from segregation of genes (44), efflux studies (24), and gene-knockout experiments (8). None of these approaches is possible in $E$. necator yet. Third, because we sampled from a diverse, recombining population in the eastern United States with very little underlying genetic structure $(5,6,19,20)$, we could conduct an association study to infer the underlying genetics of the azole sensitivity phenotypes (46). In our case, high levels of resistance to myclobutanil were highly correlated with mutations Y136F and A1119C in CYP51, but none of the residual variance was explained by expression of efflux transporter genes.

We observed a bimodal distribution of azole-sensitivity phenotypes $\left(\mathrm{EC}_{50}\right.$ values) in samples of E. necator from the eastern United States and Chile (Fig. 1). All isolates with Y136F and all but four with mutation $\mathrm{A} 1119 \mathrm{C}$ have $\mathrm{EC}_{50}$ values greater than $0.18 \mu \mathrm{g} / \mathrm{ml}$ and therefore would be considered to be resistant to myclobutanil (18). Samples of E. necator from the eastern United States were taken from a mix of commercial vineyards and wild vines, and therefore exposure to azole fungicide applications varied markedly. In previous studies, populations exposed to azole applications were composed primarily of individuals with $\mathrm{EC}_{50}$ values significantly higher than those from populations that were not exposed $(11,18,43)$. In our study, 22 of the 24 most resistant isolates came from commercial vineyards. Although we cannot rule out heterogeneous selection as a factor explaining the bimodal distribution, all isolates in the more resistant group $\left(\mathrm{EC}_{50}\right.$ values $>0.1 \mu \mathrm{g} / \mathrm{ml}$ ) had either the altered target site mutation Y136F or overexpression of CYP51 (Figs. 2 and 3). Moreover, isolates carrying $\mathrm{Y} 136 \mathrm{~F}$ also had significantly greater $C Y P 51$ expression than wild type, which may compensate for reduced CYP51 activity, as shown for mutants in Mycosphaerella graminicola (2). Although mutation Y136F and overexpression of CYP51 in E. necator explain a substantial portion of the variation in azole sensitivity, a considerable degree of variation was also found among isolates within these groups. For example, $\mathrm{EC}_{50}$ values for isolates with mutation Y136F ranged from 0.21 to $3.54 \mu \mathrm{g} / \mathrm{ml}$. This represents about a 17 -fold range, comparable to the 18-fold difference in the median $\mathrm{EC}_{50}$ values for the more-resistant versus sensitive groups. And whereas the distributions of phenotypes within our sampled populations of E. necator from the eastern United States and in Chile were bimodal, the resistant phenotypes did not exhibit the much larger resistance factors typically associated with resistance to benzimidazole, phenylamide, or QoI fungicides, caused by single mutations that have more extreme effects on resistance phenotypes. Thus, the bimodal distribution of $\mathrm{EC}_{50}$ values in E. necator is characterized by a relatively small quantitative difference between the two modes, with overlapping distributions. By contrast, the pattern observed for these other classes of fungicides is characterized by large, qualitative differences that can be easily classified into two disjunct distributions of fungicide-sensitive and fungicide-resistant isolates (22).

Haplotype diversity in CYP51 appears to be lower in the eastern United States compared to Europe. We found three mutations in four haplotypes (Table 2) in addition to the reference haplotype first described from France (15). Délye et al. (16) found three additional mutations in this gene among a collection of isolates sampled from Europe, India, and Australia, and Miazzi and Hajjeh (29) found four more in Italy. Conversely, populations of E. necator in the eastern United States are markedly more diverse for most other genetic markers $(5,20)$. The CYP51 gene is under strong selection for azole resistance because of fungicide applications in commercial vineyards, which might result in selective sweeps for multiple alleles conferring resistance. Under this scenario, azole resistance could arise multiple times, each resulting from potentially different mutations. This type of process has occurred in other grapevine pathogens. For example, identical mutations conferring resistance to QoI fungicides arose in the grapevine downy mildew pathogen, Plasmopara viticola, in two independent lineages (10).

Understanding the mechanism of azole resistance may have practical implications, especially with regard to monitoring for azole resistance and cross resistance among azoles (13). For example, surveys of E. necator in Virginia and Europe have found isolates with high resistance to azoles that do not carry $\mathrm{Y} 136 \mathrm{~F}$ $(11,15,29)$. Therefore, the strategy of monitoring populations of E. necator for $\mathrm{Y} 136 \mathrm{~F}$ to assess the risk of azole resistance (e.g., 17) will underestimate it where other resistance mechanisms are operating, as is particularly true in the eastern United States. Sensitivities to different azoles in E. necator appear to be relatively well correlated $(11,18)$, suggesting that the two dominant CYP51 mutations affecting myclobutanil resistance may have similar effects on cross resistance. However, this assumption may need further testing. Long before the mechanisms of azole resistance were known, Peever and Milgroom (31) found that cross-resistance relationships varied among different populations of Pyrenophora teres. They speculated that different alleles for resistance, 
and therefore different mechanisms, were conferring resistance in different populations. This hypothesis can now be tested in other fungi such as E. necator.

In conclusion, it appears that monitoring populations of $E$. necator in the eastern United States for azole resistance can be done relatively well by assaying for two SNPs, A495T (Y136F) and A1119C. Similarly, monitoring populations in Chile for mutation Y136F might be sufficient to predict azole resistance, although this suggestion is based on a small sample collected from a limited area in that country. However, a monitoring strategy based on detection of specific SNPs in CYP51 will not detect any new mutations that arise in the future. Additional studies on azole resistance need to be done to fully understand the mechanisms involved.

\section{ACKNOWLEDGMENTS}

This research was supported by Vaadia-BARD Postdoctoral Fellowship Award No. FI-410-2008 from the United States-Israel Binational Agricultural Research and Development Fund (BARD) to O. Frenkel, a USDA-Viticulture Consortium-East award to L. Cadle-Davidson and W. F. Wilcox, and Hatch project NYC-153410 to M. G. Milgroom. We thank J. Burr for conducting myclobutanil sensitivity assays; M. Drott for statistical analyses; and F. Riveros of the Instituto de Investigaciones Agropecuarias (INIA) in La Serena, Chile, for supplying E. necator isolates from that region. Mention of trade names or commercial products is solely for the purpose of providing specific information and does not imply recommendation or endorsement by the U.S. Department of Agriculture. USDA is an equal opportunity provider and employer.

\section{LITERATURE CITED}

1. Amrani, L., and Corio-Costet, M. F. 2006. A single nucleotide polymorphism in the beta-tubulin gene distinguishing two genotypes of Erysiphe necator expressing different symptoms on grapevine. Plant Pathol. 55:505-512.

2. Bean, T. P., Cools, H. J., Lucas, J. A., Hawkins, N. D., Ward, J. L., Shaw, M. W., and Fraaije, B. A. 2009. Sterol content analysis suggests altered eburicol 14 $\alpha$-demethylase (CYP51) activity in isolates of Mycosphaerella graminicola adapted to azole fungicides. FEMS Microbiol. Lett. 296:266273.

3. Becher, R., and Wirsel, S. R. 2012. Fungal cytochrome P450 sterol $14 \alpha-$ demethylase (CYP51) and azole resistance in plant and human pathogens. Appl. Microbiol. Biotechnol. 95:825-840.

4. Brent, K. J., and Hollomon, D. W. 2007. Fungicide Resistance: The Assessment of Risk, 2nd rev. ed Fungicide Resistance Action Committee, Croplife International, Brussels.

5. Brewer, M. T., and Milgroom, M. G. 2010. Phylogeography and population structure of the grape powdery mildew fungus, Erysiphe necator, from diverse Vitis species. BMC Evol. Biol. 10:268.

6. Brewer, M. T., Frenkel, O., and Milgroom, M. G. 2012. Linkage disequilibrium and spatial aggregation of genotypes in sexually reproducing populations of Erysiphe necator. Phytopathology 102:997-1005.

7. Cadle-Davidson, L., Wakefield, L., Seem, R. C., and Gadoury, D. M. 2010. Specific isolation of RNA from the grape powdery mildew pathogen Erysiphe necator, an epiphytic, obligate parasite. J. Phytopathol. 158:69-71.

8. Cannon, R. D., Lamping, E., Holmes, A. R., Niimi, K., Baret, P. V., Keniya, M. V., Tanabe, K., Niimi, M., Goffeau, A., and Monk, B. C. 2009. Efflux-mediated antifungal drug resistance. Clin. Microbiol. Rev. 22:291321.

9. Chaure, P., Gurr, S. J., and Spanu, P. 2000. Stable transformation of Erysiphe graminis, an obligate biotrophic pathogen of barley. Nat. Biotechnol. 18:205-207.

10. Chen, W. J., Delmotte, F., Richard-Cervera, S., Douence, L., Greif, C., and Corio-Costet, M. F. 2007. At least two origins of fungicide resistance in grapevine downy mildew populations. Appl. Environ. Microbiol. 73:5162-5172.

11. Colcol, J. F., Rallos, L. E., and Baudoin, A. B. 2011. Sensitivity of Erysiphe necator to demethylation inhibitor fungicides in Virginia. Plant Dis. 96:111-116.

12. Cools, H. J., and Fraaije, B. A. 2013. Update on mechanisms of azole resistance in Mycosphaerella graminicola and implications for future control. Pest Manage. Sci. 69:150-155.

13. Cools, H. J., Hawkins, N. J., and Fraaije, B. A. 2013. Constraints on the evolution of azole resistance in plant pathogenic fungi. Plant Pathol. 62:36-42.

14. Del Pozo, J. 2004. Historia del vino Chileno. 3rd ed. Editorial Universitaria, Santiago, Chile.

15. Délye, C., Laigret, F., and Corio-Costet, M. F. 1997. A mutation in the 14 alpha-demethylase gene of Uncinula necator that correlates with resistance to a sterol biosynthesis inhibitor. Appl. Environ. Microbiol. 63:2966-2970.

16. Délye, C., Ronchi, V., Laigret, F., and Corio-Costet, M. F. 1999. Nested allele-specific PCR primers distinguish genetic groups of Uncinula necator. Appl. Environ. Microbiol. 65:3950-3954.

17. Dufour, M.-C., Fontaine, S., Montarry, J., and Corio-Costet, M.-F. 2011. Assessment of fungicide resistance and pathogen diversity in Erysiphe necator using quantitative real-time PCR assays. Pest Manage. Sci. 67:6069.

18. Erickson, E. O., and Wilcox, W. F. 1997. Distributions of sensitivities to three sterol demethylation inhibitor fungicides among populations of Uncinula necator sensitive and resistant to triadimefon. Phytopathology 87:784-791.

19. Frenkel, O., Brewer, M. T., and Milgroom, M. G. 2010. Variation in pathogenicity and aggressiveness of Erysiphe necator from different Vitis species and geographic origins in the eastern United States. Phythopathology 100:1185-1193.

20. Frenkel, O., Portillo, I., Brewer, M. T., Péros, J.-P., Cadle-Davidson, L., and Milgroom, M. G. 2012. Development of microsatellite markers from the transcriptome of Erysiphe necator for analyzing population structure in North America and Europe. Plant Pathol. 61:106-119.

21. Gadoury, D. M., Cadle-Davidson, L., Wilcox, W. F., Dry, I., Seem, R. C., and Milgroom, M. G. 2012. Grapevine powdery mildew (Erysiphe necator): A fascinating system for the study of the biology, ecology, and the epidemiology of an obligate biotroph. Mol. Plant Pathol. 1:1-16.

22. Koeller, W., and Scheinpflug, H. 1987. Fungal resistance to sterol biosynthesis inhibitors-A new challenge. Plant Dis. 71:1066-1074.

23. Kovalchuk, A., and Driessen, A. 2010. Phylogenetic analysis of fungal $\mathrm{ABC}$ transporters. BMC Genomics 11:177.

24. Kretschmer, M., Leroch, M., Mosbach, A., Walker, A. S., Fillinger, S., Mernke, D., Schoonbeek, H. J., Pradier, J. M., Leroux, P., De Waard, M. A., and Hahn, M. 2009. Fungicide-driven evolution and molecular basis of multidrug resistance in field populations of the grey mould fungus Botrytis cinerea. PLoS Pathol. 5:e1000696.

25. Leroux, P., and Walker, A.-S. 2011. Multiple mechanisms account for resistance to sterol $14 \alpha$-demethylation inhibitors in field isolates of Mycosphaerella graminicola. Pest Manage. Sci. 67:44-59.

26. Luo, C.-X., and Schnabel, G. 2008. The cytochrome P450 lanosterol 14 $\alpha$ demethylase gene is a demethylation inhibitor fungicide resistance determinant in Monilinia fructicola field isolates from Georgia. Appl. Environ. Microbiol. 74:359-366.

27. Ma, Z., Proffer, T. J., Jacobs, J. L., and Sundin, G. W. 2006. Overexpression of the $14 \alpha$-demethylase target gene (CYP51) mediates fungicide resistance in Blumeriella jaapii. Appl. Environ. Microbiol. 72:2581-2585

28. Ma, Z. H., and Michailides, T. J. 2005. Advances in understanding molecular mechanisms of fungicide resistance and molecular detection of resistant genotypes in phytopathogenic fungi. Crop Prot. 24:853-863.

29. Miazzi, M., and Haijeh, H. R. 2011. Differential sensitivity to triadimenol of Erysiphe necator isolates belonging to different genetic groups. J. Plant Pathol. 93:729-735.

30. Palumbi, S. R. 2001. Humans as the world's greatest evolutionary force. Science 293:1786-1790.

31. Peever, T. L., and Milgroom, M. G. 1993. Genetic correlations in resistance to sterol biosynthesis-inhibiting fungicides in Pyrenophora teres. Phytopathology 83:1076-1082.

32. Pfaffl, M. W. 2001. Relative quantification. Pages 63-82. in: Real-time PCR. T. Dorak, ed. Taylor and Francis, New York.

33. Schnabel, G., and Jones, A. L. 2001. The 14 alpha-demethylase (CYP51A1) gene is overexpressed in Venturia inaequalis strains resistant to myclobutanil. Phytopathology 91:102-110.

34. Spanu, P. D., Abbott, J. C., Amselem, J., Burgis, T. A., Soanes, D. M., Stüber, K., van Themaat, E. V. L., Brown, J. K. M., Butcher, S. A., Gurr, S. J., Lebrun, M.-H., Ridout, C. J., Schulze-Lefert, P., Talbot, N. J., Ahmadinejad, N., Ametz, C., Barton, G. R., Benjdia, M., Bidzinski, P., Bindschedler, L. V., Both, M., Brewer, M. T., Cadle-Davidson, L., CadleDavidson, M. M., Collemare, J., Cramer, R., Frenkel, O., Godfrey, D., Harriman, J., Hoede, C., King, B. C., Klages, S., Kleemann, J., Knoll, D., Koti, P. S., Kreplak, J., López-Ruiz, F. J., Lu, X., Maekawa, T., Mahanil, S., Micali, C., Milgroom, M. G., Montana, G., Noir, S., O’Connell, R. J., Oberhaensli, S., Parlange, F., Pedersen, C., Quesneville, H., Reinhardt, R., Rott, M., Sacristán, S., Schmidt, S. M., Schön, M., Skamnioti, P., Sommer, H., Stephens, A., Takahara, H., Thordal-Christensen, H., Vigouroux, M., Weßling, R., Wicker, T., and Panstruga, R. 2010. Genome 
expansion and gene loss in powdery mildew fungi reveal tradeoffs in extreme parasitism. Science 330:1543-1546.

35. Stummer, B. E., and Scott, E. S. 2003. Detection of novel genotypes in progeny from a controlled cross between isolates of Uncinula necator belonging to distinct phenetic groups. Australas. Plant Pathol. 32:213218.

36. Thompson, J. D., Higgins, D. G., and Gibson, T. J. 1994. CLUSTAL W: Improving the sensitivity of progressive multiple sequence alignment through sequence weighting, position-specific gap penalties and weight matrix choice. Nucleic Acids Res. 22:4673-4680.

37. Untergasser, A., Cutcutache, I., Koressaar, T., Ye, J., Faircloth, B. C., Remm, M., and Rozen, S. G. 2012. Primer3-New capabilities and interfaces. Nucleic Acids Res. 40:e115.

38. van den Bosch, F., and Gilligan, C. A. 2008. Models of fungicide resistance dynamics. Annu. Rev. Phytopathol. 46:123-147.

39. van den Bosch, F., Oliver, R., van den Berg, F., and Paveley, N. 2014. Governing principles can guide fungicide-resistance management tactics. Annu. Rev. Phytopathol. 52:175-195.

40. Verweij, P. E., Snelders, E., Kema, G. H. J., Mellado, E., and Melchers, W. J. G. 2009. Azole resistance in Aspergillus fumigatus: A side-effect of environmental fungicide use? Lancet Infect. Dis. 9:789-795.
41. Wakefield, L., Gadoury, D. M., Seem, R. C., Milgroom, M. G., Sun, Q., and Cadle-Davidson, L. 2011. Differential gene expression during conidiation in the grape powdery mildew pathogen, Erysiphe necator. Phytopathology 101:839-846.

42. Wicker, T., Oberhaensli, S., Parlange, F., Buchmann, J. P., Shatalina, M., Roffler, S., Ben-David, R., Dolezel, J., Simkova, H., Schulze-Lefert, P., Spanu, P. D., Bruggmann, R., Amselem, J., Quesneville, H., Ver Loren van Themaat, E., Paape, T., Shimizu, K. K., and Keller, B. 2013. The wheat powdery mildew genome shows the unique evolution of an obligate biotroph. Nat. Genet. 45:1092-1096.

43. Wong, F. P., and Wilcox, W. F. 2002. Sensitivity to azoxystrobin among isolates of Uncinula necator: Baseline distribution and relationship to myclobutanil sensitivity. Plant Dis. 86:394-404.

44. Wyand, R. A., and Brown, J. K. M. 2005. Sequence variation in the CYP51 gene of Blumeria graminis associated with resistance to sterol demethylase inhibiting fungicides. Fungal Genet. Biol. 42:726-735.

45. Ypema, H. L., Ypema, M., and Gubler, W. D. 1997. Sensitivity of Uncinula necator to benomyl, triadimefon, myclobutanil, and fenarimol in California. Plant Dis. 81:293-297.

46. Zhu, C., Gore, M., Buckler, E. S., and Yu, J. 2008. Status and prospects of association mapping in plants. Plant Genome 1:5-20. 